\title{
Processing of Threat-related Information Outside the Focus of Visual Attention
}

\author{
Manuel G. Calvo and M. Dolores Castillo \\ University of La Laguna
}

\begin{abstract}
This study investigates whether threat-related words are especially likely to be perceived in unattended locations of the visual field. Threat-related, positive, and neutral words were presented at fixation as probes in a lexical decision task. The probe word was preceded by 2 simultaneous prime words ( 1 foveal, i.e., at fixation; 1 parafoveal, i.e., 2.2 deg. of visual angle from fixation), which were presented for $150 \mathrm{~ms}$, one of which was either identical or unrelated to the probe. Results showed significant facilitation in lexical response times only for the probe threat words when primed parafoveally by an identical word presented in the right visual field. We conclude that threat-related words have privileged access to processing outside the focus of attention. This reveals a cognitive bias in the preferential, parallel processing of information that is important for adaptation. Keywords: attention, emotional stimuli, parafoveal, priming
\end{abstract}

En el presente estudio se investiga si las palabras relativas a peligros se perciben fuera del campo de atención visual. En una tarea de decisión léxica se presentaron como estímulos de prueba palabras representativas de peligro, otras de contenido emocional positivo, y otras neutras. La palabra de prueba iba precedida por 2 palabras-contexto simultáneas (1 en posición foveal, en el centro del campo visual; 1 parafoveal, desplazada 2.2 grados a izquierda o derecha) durante $150 \mathrm{~ms}$. Una de las palabras-contexto era idéntica a la de prueba o bien no estaba relacionada ésta. Los resultados mostraron facilitación en la tarea de decisión léxica para las palabras de peligro cuando estaban precedidas por una palabra idéntica en el campo parafoveal derecho. Se concluye que las palabras de peligro tienen un acceso privilegiado (en comparación con las neutras y con las positivas) para ser analizadas fuera del foco de atención. Esto revela un sesgo cognitivo en el procesamiento preferente y en paralelo de la información con importancia adaptativa.

Palabras clave: atención, estímulos emocionales, parafoveal, activación

This research was supported by Grant BSO2001-3753, from the DGI, Ministerio de Ciencia y Tecnología.

We are grateful to Jukka Hyönä, Juan J. Ortells, and Margaret Dowens for their helpful comments on an earlier version of this article, and to a thoughtful reviewer.

Address correspondence concerning this article to: Manuel G. Calvo, Departamento de Psicología Cognitiva, Universidad de La Laguna, 38205 Tenerife (Spain). Phone: + 34922317 514. Fax: + 34922317 461. E-mail: mgcalvo@ull.es 
Models of emotional processing have proposed that the affective significance of all perceptual input is automatically assessed (Mathews \& Mackintosh, 1998; Robinson, 1998; Williams, Watts, MacLeod, \& Mathews, 1997). This involves pre-attentional and quick appraisal, independent of awareness and intentional control. As the affective significance of stimuli is related to their adaptive importance, automatic evaluation fulfils an important adaptive function, allowing for the rapid onset of appropriate appetitive or aversive reactions. This is especially important if the stimuli are threatening, as the primary adaptive function of organisms is survival and protection from danger. From an evolutionary perspective, the perceptual system must have been biased in the direction of a low threshold for discovering threat efficiently (Öhman, 1996). This low-threshold mechanism has been shown to involve a reduction in the exposure time needed for threatrelated stimuli to be processed. Thus, pictures of phobic stimuli and angry faces are more easily conditioned and elicit more skin conductance responses than nonphobic stimuli when presented subliminally (30-ms; see Öhman, 1999). Similarly, negatively valenced words are more accurately detected than non-negative words when presented below the level of conscious attention (15-20 ms) (Dijksterhuis \& Aarts, 2003).

The present study examines an additional characteristic of this low-threshold mechanism: a broadening of the visual field for threat-related stimuli, which involves processing of stimuli outside the spatial focus of attention. This requires some explanation of the human visual system (see, for example, Artigas, Capilla, Felipe, \& Pujol, 1995; Bruce, Green, \& Georgeson, 2003; Wandell, 1995). The fovea is a structure within the retina of the eye responsible for central vision. Although there are some discrepancies among authors regarding the different substructures within the fovea, an accepted division of the whole foveal area is: central fovea, parafovea, and perifovea. The diameter of the whole fovea is about 5.2 degrees of visual angle (henceforth, deg.), of which 2.7 deg. (i.e., approximately $2.7 \mathrm{~cm}$ of diameter of a visual object at a $60-\mathrm{cm}$ viewing distance) correspond to the central fovea. This structure is characterized by a high density of cone photoreceptors - which guarantee high visual acuity - with no rods. In contrast, in the parafovea and the periphery, the number of cones decreases whereas the number of rods increases, thus reducing acuity significantly. Central foveal vision corresponds to the spatial focus of overt attention, whereas stimuli in parafoveal vision are typically considered as "unattended." Accordingly, to address the hypothesis of a spatial broadening advantage in the processing of threat-related stimuli, we presented threatrelated words - as well as neutral and emotionally-positive words, for comparison-at eccentric locations of the visual field, more specifically, in parafoveal vision.
Prior studies have investigated parafoveal processing of neutral words (i.e., devoid of any emotional content) in psycholinguistic research. Most researchers agree that low-level information (e.g., physical characteristics, including phonological and orthographic information) is obtained parafoveally, but there is considerable disagreement regarding whether semantic information (i.e., meaning) is obtained (see Rayner White, Kambe, Miller, \& Liversedge, 2003). Thus, with priming techniques, using discrete responses (e.g., lexical decision) to a probe, facilitation or positive priming of a parafoveal prime word on a subsequent foveal probe word has been found in some studies (e.g., Kanne, 2002); others have found negative priming (e.g., Fox, 1996); in others, no priming effects have emerged (e.g., Duscherer \& Holender, 2002), or the nature of priming has been shown to vary as a function of time course (Lupiáñez, Rueda, Ruz, \& Tudela, 2000; Ortells, Abad, Noguera, \& Lupiáñez, 2001). The present study attempts to make a contribution to this complex state of affairs by introducing emotional content of the stimuli as a factor that presumably strengthens the parafoveal processing of verbal information.

More specifically, we predict that parafoveal threat-related words are more likely to be perceived than neutral words, and even than emotionally positive words. The reason lies in the adaptive importance of the events represented by these words. Thus, automatic parafoveal processing is highly functional in detecting cues of potential danger, and it is the case that threatrelated words (but not neutral words) have acquired such cueing properties by symbolic association with harmful events. This is why these words are expected to receive processing priority. A different case applies to emotionally positive words. These words are associated with appetitive events, which are also important for adaptation. However, rather than being related to the primary protective function, appetitive events (and, therefore, their corresponding positive words) are related to a secondary, preservative function, and do not comply with the urgency condition inducing automatic processing (Robinson, 1998). As a consequence, positive words are less likely to be processed in parafoveal vision than are threat-related words.

We investigated this issue by means of a priming paradigm with the following basic characteristics. First, on each trial, two prime words were presented simultaneously for $150 \mathrm{~ms}$. The foveal prime was presented at fixation; the parafoveal prime was displaced $2.2 \mathrm{deg}$. to either the right or the left of fixation. Second, after a blank interval of $150 \mathrm{~ms}$, the probe appeared at fixation (i.e., on the location of the foveal prime). The probe was a string of letters, either a word or a nonword. Participants performed a lexical decision task on the probe. Third, either one of the primes or none of them was the same word as the probe. ${ }^{1}$ However, to maximize semantic relatedness while minimizing perceptual similarity, the primes were written in lowercase letters whereas the probe was

1 The prime word was the same as the probe word in the identical condition, although presented in a different letter type, to keep the meaning while reducing perceptual similarity. Our initial intention was to use a semantic priming paradigm, with lexical associates as 
written in uppercase. Fourth, response times in the lexical decision task assessed priming effects: If the parafoveal word is perceived, then reaction times should be faster when the probe is preceded by the same word in parafoveal vision than when preceded by an unrelated word. Priming effects would, therefore, demonstrate that the unattended, parafoveal word had been processed. Fifth, the parafoveal (and the foveal) prime word could be either threat-related, emotionally positive, or neutral. If threat-related words are preferentially processed in parafoveal vision, the priming effect will be stronger for the threat words than for the other words.

With such a paradigm, the rationale to demonstrate that facilitation in lexical-decision responses reflects processing of an unattended stimulus (i.e., the parafoveal prime word) is as follows. Attention is allocated to the foveal, but not to the parafoveal prime: The viewer has to look at the former and ignore the latter, and it is in the location of the foveal prime that a subsequent probe appears. Taking into account that minimal saccade latency is $150 \mathrm{~ms}$ (see Rayner, 1998), the eyes could not move from the foveal prime and fixate foveally on the parafoveal prime. If there is facilitation of the parafoveal prime on the identical probe, this implies that the prime has been perceived without overt visual attention, that is, it must have been "seen" somehow, or covertly attended to, without having been "looked at." Accordingly, parafoveal processing is probably automatic in the sense of being fast (150 ms or less) and parallel (occurring at the same time as processing of the foveal prime), without overt controlled attention (which is devoted to the foveal prime), unintentional (the goal of the viewer is to process the foveal prime), and unconscious (participants are typically unable to identify the parafoveal words when asked to do so).

\section{Method}

\section{Participants}

Twenty-eight psychology undergraduates (22 female) participated for course credit. All were aged between 18 and 24 years.

\section{Apparatus}

Participants were presented with verbal stimuli on a super VGA 17-inch monitor connected to a Pentium III computer. Stimulus presentation and data collection were controlled by the E-Prime experimental software (Schneider, Eschman, \& Zuccolotto, 2002). Each sequence of stimuli consisted of (a) a white asterisk at the center of a screen on a dark background; (b) two white prime words (on a dark background), one at foveal fixation, replacing the asterisk, and the other in parafoveal vision, with its center displaced $2.2 \mathrm{deg}$. from central fixation horizontally, either to the right or to the left visual field; (c) a dark screen; (d) a central string of white letters (word or nonword; on a dark background) serving as the probe; and (e) verbal feedback ("correct," "incorrect," or "omission") following the participant's response to the probe. The prime and probe stimuli consisted of strings of five to seven letters. The prime words subtended a visual angle between 1.3 and $1.8 \mathrm{deg}$. horizontally, and about $0.39 \mathrm{deg}$. vertically. The probe string subtended a visual angle between 1.4 and $2.0 \mathrm{deg}$. horizontally, and $0.48 \mathrm{deg}$. vertically. Participants had their head on a chin and forehead rest, with their eyes located at a constant distance of $59 \mathrm{~cm}$ from the center of the screen. Participants responded to the probe in a lexical decision task by pressing one of two keys (for "word" and "nonword") on the computer keyboard. Response accuracy and reaction times (in milliseconds) were collected on each trial.

\section{Stimuli}

Three categories of words were presented as probes, and also as primes in the prime-probe identical condition (see Design). Of these, 48 were threat-related, 48 emotionally positive, and 48 neutral (see the Appendix). A group of 20 participants rated the emotional valence of these words. Threat, neutral, and positive words had mean ratings of $-2.10(S D=0.78),+0.08(S D=0.61)$, and $+1.94(S D=$ 0.81 ), respectively, on a scale of -3 (very negative) to +3 (very positive). A one-way ANOVA yielded a strong effect, $F(2,141)=359.96, p<.0001$. Post hoc contrasts for multiple comparisons showed significant differences between the three groups (all $p s<.0001$ ). The words of the three groups had the same length (there were 12 five-letter words, 20 six-letter words, and 16 seven-letter words in each group), and they were practically identical in number of syllables (threat: $M=2.63$; positive: $M=2.69$; neutral: $M=2.70 ; F$ $<0.5)$ and lexical frequency (Sebastián-Gallés, Martí, Cuetos, \& Carreiras, 1996; threat: $M=36.96$ occurrences per million; positive: $M=36.88$; neutral: $M=36.96 ; F<0.5)$. There

prime and probe words, but we soon noticed that this was not viable for emotional words. Positive and threat-related word categories are much more restrictive in number of exemplars than the neutral word category; in addition, the former typically have more specific meanings and nuances, which makes it difficult to find clear semantic associates. This was further complicated by the following constraints: Words should not exceed seven-letter length and should not be infrequent, and length and lexical frequency should be comparable for the three word categories. All these restrictions led us to use an identity-priming paradigm. In any case, the aim of this study was to determine whether parafoveal threat words are especially likely to be perceived. We made no assumptions about whether this involves semantic analysis of the specific meaning of the parafoveal words (see Discussion). 
were also nonword stimuli (i.e., pseudo-words in which one letter of a valid word was changed), which were used only as probes (not as primes) in $25 \%$ of the trials. We used this low nonword ratio to minimize postlexical strategies (see Neely, 1991; Ortells et al., 2001).

\section{Design}

For parafoveal trials, we used a within-subjects factorial design, with emotional Valence of the probe (threat vs. positive vs. neutral) $\times$ prime-probe Relatedness (identical vs. unrelated) $\times$ Visual Field of the parafoveal prime (left vs. right) as factors. On trials in which the effect of foveal primes was investigated, the visual-field factor was removed. For each participant, following 30 practice trials, 192 trials were presented (144 involving probe words and 48 involving nonwords) in two blocks, with a rest interval. Each participant received 48 probe words of each of the three valence categories; half of the probes were preceded by an identical parafoveal prime, either in the left or the right visual field. The trials were randomly assigned to blocks and randomly presented within each block for each participant. See an example in Table 1.

\section{Procedure}

Figure 1 depicts the sequence of events in each trial. A trial started with a central asterisk as a fixation point. We encouraged participants to maintain central gaze fixation, as their lexical decision task would have to be performed on the probe appearing at that point. The asterisk first remained for $500 \mathrm{~ms}$, then there was a $100-\mathrm{ms}$ blank interval, and the asterisk appeared again for $100 \mathrm{~ms}$. Following offset of the asterisk, both the foveal and the parafoveal prime were displayed simultaneously for $150 \mathrm{~ms}$, followed by a 150 -ms blank interval. The 150-ms display of the primes served to prevent eye movements to the parafoveal prime, and thus make sure that only the foveal prime could be foveally seen. Then the probe appeared at foveal fixation for $1250 \mathrm{~ms}$ or until the participant responded whether the probe was a word or a nonword, as rapidly as possible. Visual feedback appeared for $750 \mathrm{~ms}$. The intertrial interval was $2 \mathrm{~s}$.

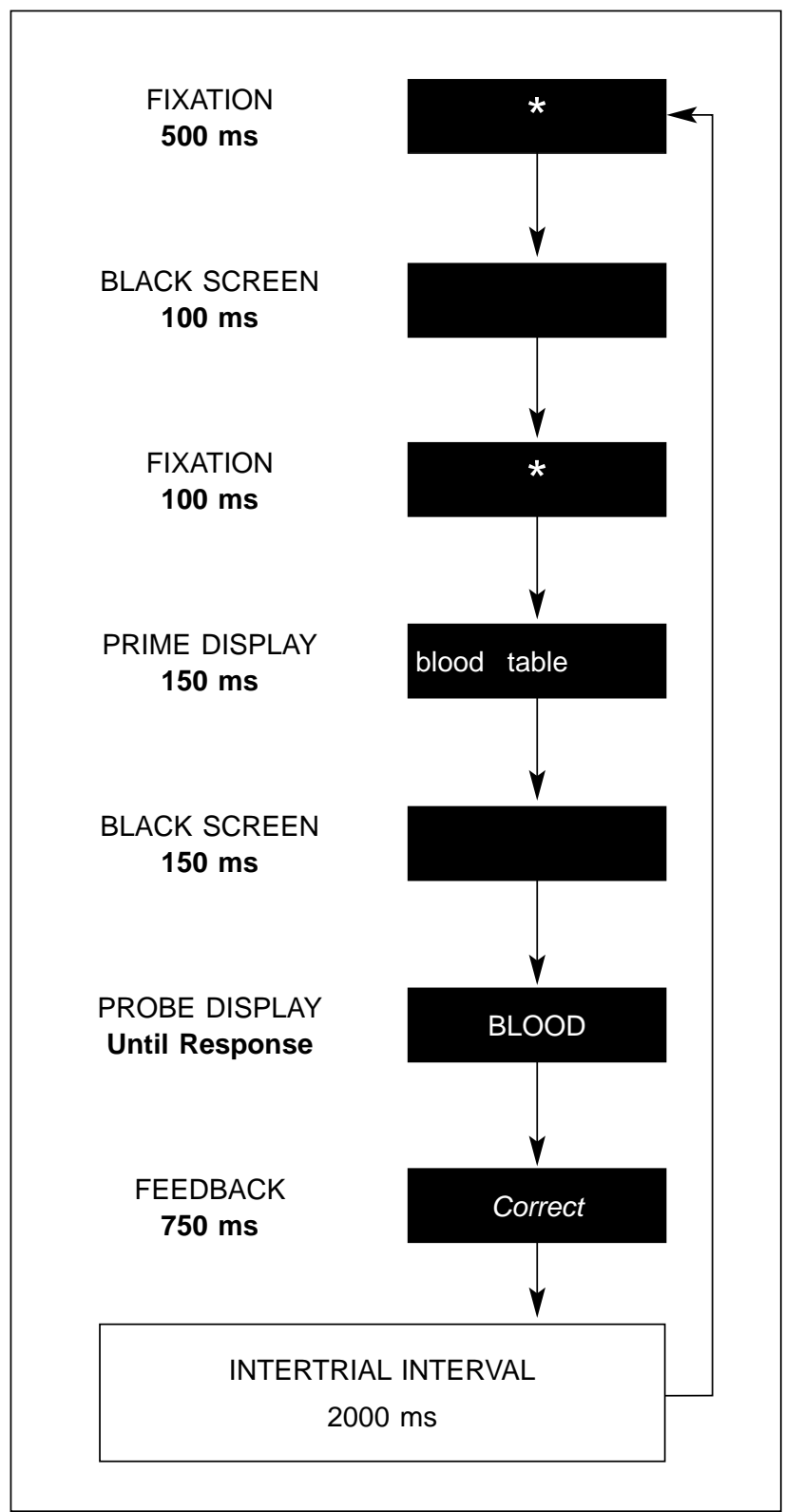

Figure 1. Sequence of events on each trial. In the Prime Display, the parafoveal word (e.g., blood) was presented either on the left or on the right.

Table 1

Example of Combinations of Experimental Conditions for Each Type of Word

\begin{tabular}{|c|c|c|c|c|c|c|}
\hline \multirow{4}{*}{$\begin{array}{l}\text { Valence of Parafoveal } \\
\text { Prime }\end{array}$} & \multicolumn{6}{|c|}{ Relatedness of Parafoveal Prime-Probe } \\
\hline & \multicolumn{3}{|c|}{ Identical } & \multicolumn{3}{|c|}{ Unrelated } \\
\hline & \multicolumn{2}{|c|}{ Prime } & \multirow[b]{2}{*}{ Probe } & \multicolumn{2}{|c|}{ Prime } & \multirow[b]{2}{*}{ Probe } \\
\hline & Foveal & Parafoveal & & Foveal & Parafoveal & \\
\hline Threat & liquid & cancer & CANCER & liquid & vision & CANCER \\
\hline Positive & liquid & caress & CARESS & liquid & vision & CARESS \\
\hline Neutral & liquid & center & CENTER & liquid & vision & CENTER \\
\hline
\end{tabular}


Table 2

Mean Lexical Decision Times (in ms) for Probe Words as a Function of Prime Location (Foveal or Parafoveal), Probe Valence (Threat, Positive, or Neutral), and Prime-Probe Relatedness (Identical or Unrelated)

\begin{tabular}{lcccccc}
\hline & \multicolumn{3}{c}{ Foveal Prime } & \multicolumn{3}{c}{ Parafoveal Prime } \\
\cline { 2 - 7 } Valence & Identical & Unrelated & U-I & Identical & Unrelated & U-I \\
\hline Threat & 580 & 693 & +113 & 682 & 697 & +15 \\
Positive & 586 & 677 & +91 & 671 & 676 & 68 \\
Neutral & 599 & 697 & +98 & 669 & 680 & +11 \\
\hline
\end{tabular}

Note. Data are collapsed across visual field (visual field differences are shown in Figure 2). U-I = Difference Unrelated - Identical (i.e., activation or priming scores in the identical prime-probe condition).

\section{Results}

Errors and omissions in the lexical decision task occurred in $3.8 \%$ of word trials. An additional cutoff was performed on reaction times shorter than $350 \mathrm{~ms}$ (less than $0.5 \%$ of cases). Analyses of variance on the percentage of errors and omissions, and on reaction times for nonwords, as a function of the experimental factors yielded no significant effect.

ANOVAs were conducted on correct reaction times in the lexical decision task for foveal primes and parafoveal primes separately (see mean scores in Table 2). For foveal primes, the probe Valence $\times$ prime-probe Relatedness ANOVA yielded only a strong effect of relatedness, $F(1$, 27) $=157.04, p<.0001, \eta_{\mathrm{p}}{ }^{2}=.85 .^{2}$ Reaction times were faster for probe words when preceded by the same word in foveal fixation $(M=588 \mathrm{~ms})$ than when preceded by an unrelated word $(M=689 \mathrm{~ms})$. Though strong-and expected-this foveal effect is of no theoretical interest for the specific purpose of this study. It is important to note, however, that there were no significant effects of valence or an interaction.

In contrast, for parafoveal primes, a Valence $\times$ Relatedness $\times$ Visual Field ANOVA produced a relatedness by visual field interaction, $F(1,27)=4.33, p<.05, \eta_{\mathrm{p}}{ }^{2}=$ .14. A subsequent ANOVA for each visual field separately revealed a relatedness effect only in the right visual field, $F(1,27)=12.81, p<.001, \eta_{\mathrm{p}}{ }^{2}=.32$, with shorter reaction times when the parafoveal prime was the same as the probe $(M=669 \mathrm{~ms})$ than when the prime was unrelated $(M=$ $690 \mathrm{~ms}$ ). Activation scores were computed by subtracting reaction times for the probe in the identical condition from those in the unrelated condition (see Table 2 and Figure 2). A positive difference score indicates that the prime facilitated the processing of the probe (i.e., positive priming); a negative score shows negative priming effects. In the right visual field, activation was significant for threat words, $t(27)=3.52, p<.01$, but not for neutral words, $t(27)=1.49, p=.15$, or positive words, $t(27)=1.18, p=$ .24. The lack of a valence by relatedness interaction, $F(2$, 26) $=1.10, p=.35, \eta_{\mathrm{p}}^{2}=.078$, is due to the fact that there was the same trend of parafoveal positive priming for all words, though the effect reached statistical significance only for threat-related words.

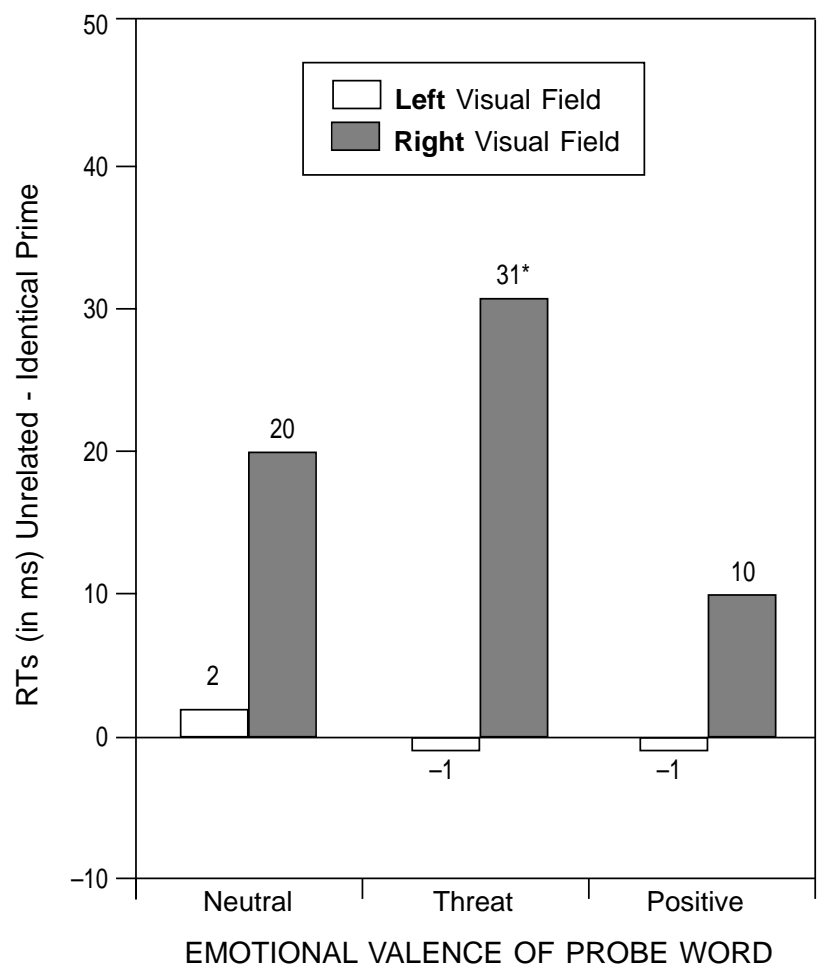

Figure 2. Activation scores for parafoveal primes as a function of valence of probe word and visual field. Positive scores indicate positive priming (i.e., facilitation) in the identical prime-probe condition. Asterisks show significant differences.

2 Partial eta squared (i.e., $\eta_{\mathrm{p}}{ }^{2}$ ) is a measure of effect size that reflects the proportion of variance that is accounted for by specific factors or their interaction. 


\section{Discussion}

The results showed positive parafoveal priming, as evidenced by a reduction in lexical decision times on the probe word following an identical (vs. unrelated) prime word. This occurred both when the prime appeared in foveal and in parafoveal location, hence revealing that parafoveal words presented $2.2 \mathrm{deg}$. out of fixation were processed. ${ }^{3}$ Our findings are consistent with those of Di Pace, Longoni, and Zoccolotti (1991), Fuentes and Tudela (1992), Kanne (2002), Ortells et al. (2001), using comparable short stimulus onset asynchronies (SOAs) - ranging from 226 to $320 \mathrm{~ms}-$ and no task to be performed on the foveal prime (apart from paying attention to it). With longer SOAs, positive priming has been found to turn into negative priming (Lupiáñez et al., 2000; Ortells et al., 2001); with an additional task on the foveal prime, either no priming or negative priming has been observed (see Duscherer \& Holender, 2002; Fox, 1996).

Nevertheless, the analysis of activation scores demonstrated that the effect reached statistical significance only for the threat-related words; there was a clear but not reliable trend for the neutral and the positive words. This is in line with our central predictions: Parafoveal priming should be especially likely for threat-related words. There are two possible explanations for this priming effect. One assumes that meaning is the factor responsible for the parafoveal advantage of threat words. That is, these words would be semantically processed as primes in parafoveal vision, and this semantic activation would then facilitate lexical access when the identical probe appears. There is, however, an alternative explanation, according to which our priming effects could have been determined by the orthographic or phonological similarity between the prime and the probe rather than by meaning. That is, although the prime and the probe words were visually non-matching (as one was written in lowercase and the other in uppercase letter), they obviously had the same phonological and orthographic codes in the identical prime-probe condition.

Ideally, a semantic priming paradigm (i.e., a prime word lexically or semantically associated with the probe word), instead of a repetition-priming paradigm (i.e., orthographically and semantically identical prime-probe), might have allowed us to determine whether the parafoveal threat words were semantically processed. Both the semantic and the repetition priming paradigms have been used in prior research (e.g.,
Kanne, 2002; MacLeod, Chiappe, \& Fox, 2002). We chose the latter paradigm for both practical and theoretical reasons (see Footnote 1). Essentially, the available number of threat words that can be used as stimuli is low (to our knowledge, no prior semantic priming study has used emotional words). Furthermore, most threat words involve specific meanings and nuances, which prevents them from being interchanged with other words as equivalent semantic associates. This implies that semantic priming (i.e., facilitation in the lexical decision to a semantically related prime-probe pair) could not occur due to the relationship not being close enough. In fact, recent research using a semantic priming paradigm has shown that effects of parafoveal neutral words are obtained only when the prime and the probe are highly related (Abad, Noguera, \& Ortells, 2003). Accordingly, the semantic priming paradigm might not be sensitive to assess semantic processing of the parafoveal threat words. Actually, there could be semantic processing of the parafoveal word, but the activation of this meaning would not affect the processing of the probe due to subtle semantic differences between these words in the threat category.

In any case, either if a semantic or an orthographic mechanism is involved in the priming effects for threat words, this effect reveals that these words are especially likely to be perceived in parafoveal vision, in comparison with neutral and positive words. Word length and lexical frequency - two important factors affecting lexical decision times-were practically identical for the three types of words. Moreover, there was also prime-probe orthographic identity for the positive and the neutral words, yet the priming effects were significant only for the threat-related words. So this implies that orthographic similarity was not the only factor responsible for the enhanced priming effects for threat words. Otherwise, such priming would have being significant also for the positive and the neutral words. So it was probably the meaning of parafoveal threat words that made a difference, making these words as primes especially accessible to analysis by the cognitive system, which then speeded up their subsequent lexical identification as probes.

Our findings of parafoveal processing of threat-related stimuli are consistent with current models about the processing of emotional stimuli. These models agree that the affective valence of stimuli is automatically assessed by mechanisms such as the Significance Evaluator (Öhman, 1996), the Affective Decision Mechanism (Williams et al.,

\footnotetext{
3 We should remind readers here that the diameter of our parafoveal words was between 1.3 and 1.8 deg.- - depending on word lengthand that there were $2.2 \mathrm{deg}$. from the center of the parafoveal word to the center of the foveal word (i.e., the fixation point). It follows that the radius from the inner boundaries of the parafoveal words (i.e., last letter of left words and initial letter of right words) and the central fixation point was between 1.3 and $1.65 \mathrm{deg}$. Given that that the rod-free central fovea encompasses $2.7 \mathrm{deg}$. of diameter (see the introduction), this leaves a radius of $1.35 \mathrm{deg}$. from the center of fixation to the left and the right extremes. Accordingly, one or two letters of the longest parafoveal words might have actually been seen foveally, while the rest of the letters clearly fell in truly paravofeal locations. This will have implications for the explanation of the right visual field advantage (see text).
} 
1997), the Valence Evaluation System (Mogg \& Bradley, 1998), or the Threat Evaluation System (Mathews \& Mackintosh, 1998). These models have emphasized the preattentional functioning of a perceptual system that can detect threat efficiently. Thus, affective appraisal would be performed without the intervention of controlled resources, involuntarily and unconsciously. This automatic processing would be possible due to an in-built lowthreshold mechanism allowing for the detection of threatrelated cues of minimal intensity. This explains why threatrelated subliminal stimuli are more likely to be detected than neutral or even positive stimuli (e.g., Dijksterjuis \& Aarts, 2003; Öhman, 1999). The results from the present study are not only consistent with this theoretical approach, but they also make a contribution, by extending the functions of the proposed low-threshold mechanism. Thus, the parafoveal priming of threatening words implies another automatic characteristic, namely, parallel processing, as the parafoveal word must be processed while the viewer is attending to the foveal word. Accordingly, one way the low-threshold mechanism operates is by allowing briefly presented threat stimuli to be detected, as proposed by the models. This makes the perceptual system faster in activation. Another way would be by allowing more eccentric threat stimuli to be processed, which implies a broadening of attentional span, as revealed by our findings. This makes the perceptual system larger in capacity. Both the temporal speeding and the spatial broadening would contribute to increasing the sensitivity of the cognitive system to threat-related stimuli.

Nevertheless, this parafoveal processing advantage of the threat-related stimuli seems to be limited to the right visual field, as the priming effect did not emerge in the in the left hemifield. Some prior studies have also shown an advantage of the right visual field in the recognition of words, using a lexical decision task. Thus, faster responses have been found when probe words are precued by a visual signal on the left (therefore, the word appeared on the right; Mondor \& Bryden, 1992; Ortells, Tudela, Noguera, \& Abad, 1998), and when primed by a word appearing on the right (Kanne, 2002). This reveals an asymmetry in the functional field of view, or perceptual span, favoring the right hemifield (see a review in Lupiáñez, Madrid, \& Rueda, 1999). There are several explanations for this right visual field superiority (Fuentes \& Santiago, 1999; Lupiáñez et al., 1999), with which our results are compatible: the brain left-hemisphere dominance for word processing and the asymmetry of perceptual span in reading, which extends more to the right than to the left of fixation, possibly enhanced by rightward reading habits. There is an additional reason for the right visual field advantage in our study if we take into account the possibility that the inner boundaries of our parafoveal words could be seen foveally (see Footnote 3 ). This would imply that the beginning of the word in the right visual field could fall in foveal vision (whereas its end would be in the parafovea); in contrast, the opposite would apply to the word in the left visual field. As the beginning of a word is more informative than the end regarding its morphology (Brysbaert, Vitu, \& Schroyens, 1996), the whole word can be guessed or reconstructed more easily and/or quickly forwards than backwards. This would explain why the priming effects for all three types of words (positive, neutral, and negative) were greater when the prime appeared in the right than in the left visual field.

In conclusion, the aim of this study was to assess whether threat-related stimuli have privileged access to analysis by the cognitive system outside the focus of visual spatial attention. The results confirmed this prediction by showing significant priming of probe threat words by parafoveal prime threat words, whereas this effect was not reliable for neutral and positive words. Presumably, threat-related words are especially likely to be perceived in unattended, or more eccentric, locations of the visual field because they are associated with important events concerning survival. The cognitive system would be biased to preferentially process this type of stimuli in order to facilitate early and parallel detection of threat cues, and therefore prompt preparatory defensive responses. This type of mechanism is of obvious adaptive importance within the functional role of the cognitive system.

\section{References}

Abad, M.J., Noguera, C., \& Ortells, J J. (2003). Influence of primetarget relationship on semantic priming effects from words in a lexical-decision task. Acta Psychologica, 113, 283-295.

Artigas, J.M., Capilla, P. Felipe, A., \& Pujol, J. (1995). Optica fisiológica. Psicofísica de la visión. Madrid: McGraw-Hill.

Bruce, V., Green, P.R., \& Georgeson, M.A. (2003). Visual perception $\left(4^{\text {th }}\right.$ ed.). Hove, UK: Psychology Press.

Brysbaert, M., Vitu, F., \& Schroyens, W. (1996). The right visual field advantage and the optimal viewing position effect: On the relation between foveal and parafoveal word recognition. Neuropsychology, 10, 385-395.

Dijksterjuis, A., \& Aarts, H. (2003). On wildebeests and humans: The preferential detection of negative stimuli. Psychological Science, 14, 14-18.

Di Pace, E., Longoni, A.M., \& Zoccolotti, P. (1991). Semantic processing of unattended parafoveal words. Acta Psychologica, 77, 21-34

Duscherer, K., \& Holender, D. (2002). No negative semantic priming from unconscious flanker words in sight. Journal of Experimental Psychology: Human Perception and Performance, 28, 839-853.

Fox, E. (1996). Cross-language priming from ignored words: Evidence from a common representational system in bilinguals. Journal of Memory and Language, 35, 353-370.

Fuentes, L.J., \& Santiago, E. (1999). Spatial and semantic inhibitory processing in schizophrenia. Neuropsychology, 13, 259-270. 
Fuentes, L.J., \& Tudela, P. (1992). Semantic processing of foveally and parafoveally presented words in a lexical decision task. The Quarterly Journal of Experimental Psychology, 45A, 299-322.

Kanne, S. (2002). The role of semantic, orthographic, and phonological prime information in unilateral visual neglect. Cognitive Neuropsychology, 19, 245-261.

Lupiáñez, J., Madrid, E., \& Rueda, M.R. (1999). Asimetría en la amplitud perceptual: Implicaciones para la presentación en parafóvea. Estudios de Psicología, 62, 101-110.

Lupiáñez, J., Rueda, M.R., Ruz, M., \& Tudela, P. (2000). Processing of attended and ignored words in the parafovea: Inhibitory aspects of semantic processing. Psicologica, 21, 233-256.

MacLeod, C.M., Chiappe, D.L., \& Fox, E. (2002). The crucial roles of stimulus matching and stimulus identity in negative priming. Psychonomic Bulletin and Review, 9, 521-528.

Mathews, A., \& Mackintosh, B. (1998). A cognitive model of selective processing in anxiety. Cognitive Therapy and Research, 22, 539-560.

Mogg, K., \& Bradley, B. (1998). A cognitive-motivational analysis of anxiety. Behaviour Research and Therapy, 36, 809-848.

Mondor, T.A., \& Bryden, M.P. (1992). On the relation between visual spatial attention and visual field asymmetries. The Quarterly Journal of Experimental Psychology, 44A, 529-555.

Neely, J.H. (1991). Semantic priming effects in visual word recognition: A selective review of current findings and theories. In D. Besner \& G.W. Humphreys (Eds.), Basic processes in reading: Visual word recognition (pp. 264-336). Hillsdale, NJ: Erlbaum.

Öhman, A. (1996). Preferential preattentive processing of threat in anxiety: Preparedness and attentional biases. In R.M. Rapee (Ed.), Current controversies in anxiety disorders (pp. 253-290). New York: Guilford Press.

Öhman, A. (1999). Distinguishing unconscious from conscious emotional processes: Methodological considerations and theoretical implications. In T. Dalgleish \& M. Power (Eds.), Handbook of cognition and emotion (pp. 321-352). Chichester, UK: Wiley.
Ortells, J.J., Abad, M.J., Noguera, C., \& Lupiáñez, J. (2001). Influence of prime-probe stimulus onset asynchrony and prime precuing manipulations on semantic priming effects with words in a lexical decision task. Journal of Experimental Psychology: Human Perception and Performance, 27, 75-91.

Ortells, J.J., Tudela, P., Noguera, C., \& Abad, M.J. (1998). Attentional orienting within the visual field in a lexical decision task. Journal of Experimental Psychology: Human Perception and Performance, 24, 1675-1689.

Rayner, K. (1998). Eye movements in reading and information processing: 20 years of research. Psychological Bulletin, 124, $372-422$.

Rayner, K., White, S.J., Kambe, G., Miller, B., \& Liversedge, S.P. (2003). On the processing of meaning from parafoveal vision during eye fixations in reading. In J. Hyönä, R. Radach \& H. Deubel (Eds.), The mind's eye: Cognitive and applied aspects of eye movement research (pp. 213-234). Oxford: Elsevier Science.

Robinson, M.D. (1998). Running from William James' bear: A review of preattentive mechanisms and their contribution to emotional experience. Cognition and Emotion, 12, 667-696.

Schneider, W., Eschman, A., \& Zuccolotto, A. (2002). E-Prime User's Guide. Pittsburgh, PA: Psychology Software Tools.

Sebastián-Gallés, N., Martí, M.A., Cuetos, F., \& Carreiras, M. (1996). LEXESP: Una base de datos informatizada del español. Barcelona, Spain: University of Barcelona.

Wandell, B.A. (1995). Foundations of vision. Sunderland, MA: Sinauer.

Williams, J.M.G., Watts, F.N., MacLeod, C., \& Mathews, A. (1997). Cognitive psychology and emotional disorders ( $2^{\text {nd }}$ ed.). Chichester, UK: Wiley.

Received: October 14, 2004 Review received: February 2, 2005 Accepted: February 10, 2005 


\section{Appendix}

\section{LIST OF WORDS USED AS EXPERIMENTAL STIMULI}

\section{THREAT WORDS}

Ataúd (coffin)

Odiar (hate)

Pelea (fight)

Tumor (tumor)

Cruel (cruel)

Tumba (tomb)

Bomba (bomb)

Matar (kill)

Virus (virus)

Morir (die)

Dolor (pain)

Miedo (fear)

Azotar (lash)

Víbora (viper)

Atraco (mugging)

Paliza (beating)

Agonía (agony)

Veneno (poison)

Ladrón (thief)

Alarma (alarm)

Pánico (panic)

Llorar (cry)

Herida (wound)

Crimen (crime)

Horror (horror)

Sufrir (suffer)

Terror (terror)

Cárcel (jail)

Cáncer (cancer)

¡Fuego! (fire!)

Sangre (blood)

Guerra (war)

Víctima (victim)

Fusilar (shoot)

Violada (raped)

Asfixia (suffocation)

Ahogado (drowned)

Socorro (help!)

Maligno (malignant)

Disparo (shot)

Tortura (torture)

Infarto (stroke)

Asesino (murder)

Castigo (punishment)

Cadáver (corpse)

Enemigo (enemy)

Enfermo (ill)

Peligro (danger)
POSITIVE WORDS

Tarta (cake)

Besar (kiss)

Gozar (enjoy)

Guapo (handsome)

Bello (beautiful)

Humor (humor)

Ganar (win)

Salud (health)

Éxito (success)

Feliz (happy)

Juego (play)

Bueno (good)

Halago (compliment)

Animar (cheer up)

Óptimo (optimum)

Gustar (like)

Agrado (pleasant)

Elogio (praise)

Mérito (merit)

Genial (great)

Tesoro (treasure)

Abrazo (hug)

Afecto (affection)

Bonito (nice)

Amable (kind)

Cariño (love)

Ayudar (helpful)

Regalo (gift)

Premio (prize)

Fiesta (feast)

Placer (pleasure)

Suerte (luck)

Delicia (delight)

Admirar (admire)

Aplauso (applause)

Caricia (caress)

Erótico (erotic)

Acierto (correct)

Riqueza (wealth)

Campeón (champion)

Talento (talent)

Hermoso (lovely)

Ilusión (hope)

Amistad (friendship)

Triunfo (triumph)

Fortuna (fortune)

Alegría (joy)

Sonrisa (smile)
NEUTRAL WORDS

Gorro (hat)

Sumar (add)

Bolso (bag)

Cable (cable)

Barba (beard)

Oreja (ear)

Poema (poem)

Andar (walk)

Nariz (nose)

Mirar (look)

Carta (letter)

Suelo (floor)

Alisar (smooth)

Brocha (paintbrush)

Cheque (cheque)

Jinete (horseman)

Bronce (bronze)

Cartón (cardboard)

Zapato (shoe)

Ligero (light)

Pájaro (bird)

Ensayo (trial)

Bigote (moustache)

Hombro (shoulder)

Tienda (tent)

Cerrar (close)

Puente (bridge)

Puerto (harbor)

Teatro (theater)

Modelo (model)

Camino (path)

Mañana (morning)

Montaña (mountain)

Acercar (approach)

Albañil (bricklayer)

Cepillo (brush)

Teclado (keyboard)

Impreso (form)

Cemento (cement)

Algodón (cotton)

Sendero (track)

Asfalto (pavement)

Febrero (February)

Pintura (paint)

Similar (similar)

Mensaje (message)

Próximo (next)

Líquido (liquid) 